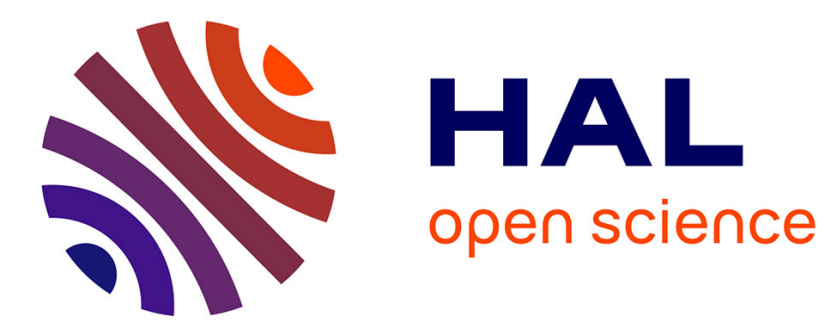

\title{
Reverse saturable absorption in solid xerogel matrices
}

Florian Bentivegna, Michael Canva, Patrick Georges, Alain Brun, Frédéric Chaput, Laurent Malier, Jean-Pierre Boilot

\section{To cite this version:}

Florian Bentivegna, Michael Canva, Patrick Georges, Alain Brun, Frédéric Chaput, et al.. Reverse saturable absorption in solid xerogel matrices. Applied Physics Letters, 1993, 62 (15), pp.1721-1723. 10.1063/1.109585 . hal-00668880

\section{HAL Id: hal-00668880 \\ https://hal-iogs.archives-ouvertes.fr/hal-00668880}

Submitted on 10 Feb 2012

HAL is a multi-disciplinary open access archive for the deposit and dissemination of scientific research documents, whether they are published or not. The documents may come from teaching and research institutions in France or abroad, or from public or private research centers.
L'archive ouverte pluridisciplinaire HAL, est destinée au dépôt et à la diffusion de documents scientifiques de niveau recherche, publiés ou non, émanant des établissements d'enseignement et de recherche français ou étrangers, des laboratoires publics ou privés. 


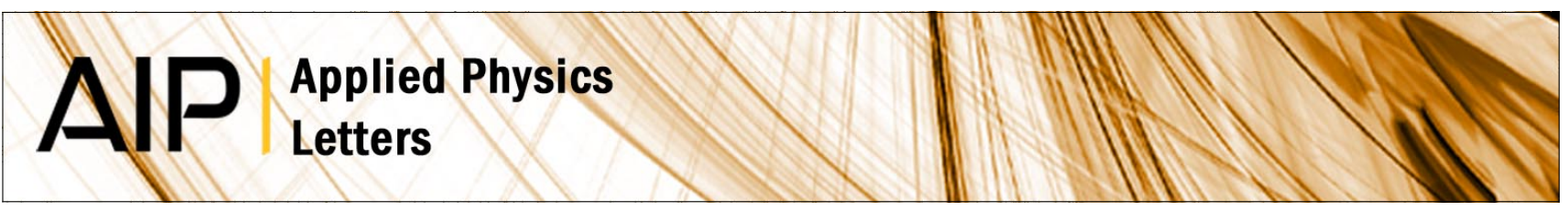

\section{Reverse saturable absorption in solid xerogel matrices}

Florian Bentivegna, Michael Canva, Patrick Georges, Alain Brun, Frédéric Chaput et al.

Citation: Appl. Phys. Lett. 62, 1721 (1993); doi: 10.1063/1.109585

View online: http://dx.doi.org/10.1063/1.109585

View Table of Contents: http://apl.aip.org/resource/1/APPLAB/v62/i15

Published by the American Institute of Physics.

\section{Related Articles}

Fabrication of disconnected threedimensional silver nanostructures in a polymer matrix Appl. Phys. Lett. 100, 063120 (2012)

Enhancement of linear and nonlinear optical properties of deoxyribonucleic acid-silica thin films doped with rhodamine

Appl. Phys. Lett. 99, 243304 (2011)

Enhancement of linear and nonlinear optical properties of deoxyribonucleic acid-silica thin films doped with rhodamine

APL: Org. Electron. Photonics 4, 275 (2011)

Solid-immersion-lens-enhanced nonlinear frequency-variation mapping of a silicon integrated-circuit Appl. Phys. Lett. 99, 193103 (2011)

A microfiber cavity with minimal-volume confinement

Appl. Phys. Lett. 99, 051105 (2011)

\section{Additional information on Appl. Phys. Lett.}

Journal Homepage: http://apl.aip.org/

Journal Information: http://apl.aip.org/about/about_the_journal

Top downloads: http://apl.aip.org/features/most_downloaded

Information for Authors: http://apl.aip.org/authors

\section{ADVERTISEMENT}

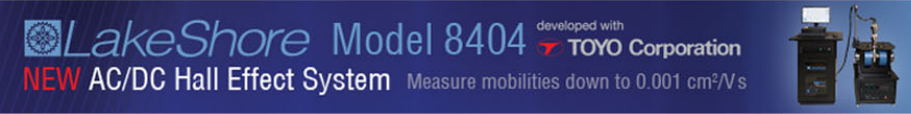




\title{
Reverse saturable absorption in solid xerogel matrices
}

\author{
Florian Bentivegna, Michael Canva, Patrick Georges, and Alain Brun \\ Groupe d'Optique Non Linéaire, Institut d'Optique Théorique et Appliquée, Centre National \\ de la Recherche Scientifique, URA 14 Bâtiment 503, BP 147, 91403 Orsay Cedex, France
}

Frédéric Chaput, Laurent Malier, and Jean-Pierre Boilot

Groupe de Chimie du Solide, Laboratoire de Physique de la Matière Condensée. Ecole Polytechnique,

Centre National de la Recherche Scientifique, URA D-1254, 91128 Palaiseau Cedex, France

(Received 22 September 1992; accepted for publication 20 January 1993)

\begin{abstract}
Aluminophthalocyanine (APC) and fullerene carbon $60\left(\mathrm{C}_{60}\right)$ have been studied encaged in different silica matrices. The reverse saturable absorption properties of these doped xerogels have been compared to those of reference solutions of $\mathrm{APC}$ and $\mathrm{C}_{60}$. We show that reverse saturable absorber molecules retain their properties even when they are enclosed in the pores of a solid xerogel matrix.
\end{abstract}

In most dye chromophores, an increase in incident intensity leads to an increase in the transmission which becomes nonlinear at high intensities. Such molecules are therefore called saturable absorbers. Some chromophores, on the contrary, become less transparent as the incident intensity increases and are called reverse saturable absorbers. The use of both types of chromophores has been suggested in the last few years, especially in laser cavities as mode locking or pulse-shaping media ${ }^{1-3}$ or as optical limiters. $^{4}$

Most authors propose a simple energy-level model to describe saturable as well as reverse saturable absorption (Fig. 1). The incident photons excite absorber molecules from the ground state $S_{0}$ to the first excited state $S_{1}$ with an absorption cross-section $\sigma_{g r}(\lambda)$. The excited molecules then relax very rapidly to the lowest energy levels of $S_{1}$. From there the population of the first excited state may either decay to the ground state with an absorption recovery time $\tau_{g r}$ or be excited to a higher excited state $S_{2}$ by absorbing incident photons; this excited-state absorption is characterized by a cross-section $\sigma_{e x}(\lambda)$. At a given incident wavelength $\lambda$, if $\sigma_{g r}>\sigma_{e x}$, the molecule behaves like a saturable absorber. On the opposite, if the absorption cross section from the first excited state $S_{1}$ up to a higher excited state $S_{2}$ is larger than the absorption cross section from the ground state $S_{0}$ to the first excited state $S_{1}\left(\sigma_{e x}>\sigma_{g r}\right)$, the molecule is a reverse saturable absorber. Note that two types of applications of a reverse saturable absorber in a laser cavity exist depending on the values of the first excited state recovery time $\tau_{e x}$ and of the incident pulse width $\tau_{L}$ : molecules with $\tau_{e x}>\tau_{L}$ may be used for pulse smoothing or power limitation, and reverse saturable absorbers with $\tau_{e x}<\tau_{L}$ lead to pulse shortening or energy limitation.

Reverse saturable absorption has already been observed with many molecules in solution. ${ }^{5,6}$ Do these molecules still behave like reverse saturable absorbers when they are enclosed in a solid medium, for example in a xerogel matrix, as recent results ${ }^{7}$ seem to indicate with APC? Should this be the case, their application as optical limiters in solid state lasers would be of great interest. To answer this question, we have studied two types of reverse saturable absorbers encaged in the pores of a gel matrix: organic ones, like aluminophthalocyanine (APC), and in- organic ones, e.g., fullerene carbon $60\left(\mathrm{C}_{60}\right)$.

Oxide gel matrices have been prepared by the sol-gel method using metal alkoxides as precursors. In all cases, the initial sol was prepared with a mixture of both silicon (Si) and zirconium ( $\mathrm{Zr})$ precursors in an organic solvent: tetraethoxysilane $\mathrm{Si}\left(\mathrm{OC}_{2} \mathrm{H}_{5}\right)_{4}$ (TEOS) or one of its organic-inorganic hybrid derivatives was used as a silicon precursor, while zirconium butoxide $\left[\mathrm{Zr}(\mathrm{OBu})_{4}\right]$ provided zirconium atoms. Chromophores were added to this initial solution: aluminophthalocyanine was enclosed in three different types of matrices derived from either TEOS, methyltriethoxysilane (MTEOS) or vinyltriethoxysilane (VTEOS), and the solvent used was ethanol (EtOH). For $\mathrm{C}_{60}$, we used benzene $\left(\mathrm{C}_{6} \mathrm{H}_{6}\right)$ as the solvent and the silicon precursor was vinyltriethoxysilane (VTEOS). The initial doping concentrations were $4 \times 10^{-4} \mathrm{~mol} / \ell$ for $\triangle P C$ and $1.4 \times 10^{-5} \mathrm{~mol} \ell \ell$ for $\mathrm{C}_{60}$.

Gel samples were obtained by slow hydrolysis condensation of such alkoxide solutions in a wet atmosphere. As previously reported, ${ }^{8}$ this process leads after complete drying to clear and dense xerogels which exhibit a closed porosity. In xerogels, organic groups (methyl- $\mathrm{CH}_{3}$ or vinyl$\mathrm{CH}=\mathrm{CH}_{2}$ ) still remain attached to the silicon atoms and may induce modifications on chromophore molecule/gel

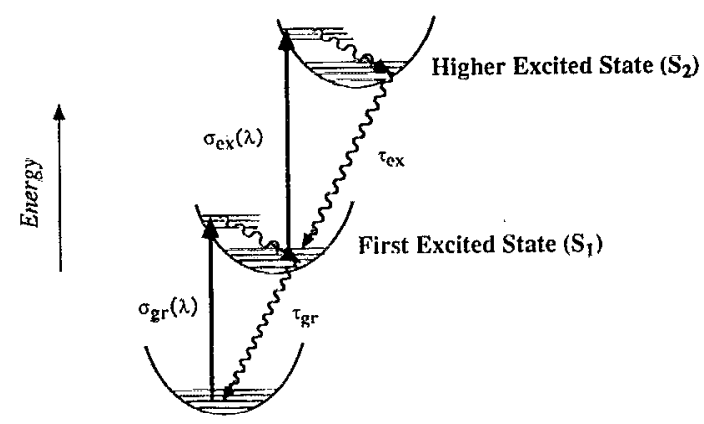

Ground State $\left(S_{0}\right)$

Nuclear Configuration Coordinate

FIG. 1. Classical energy-level model of saturable and reverse saturable absorbers. 

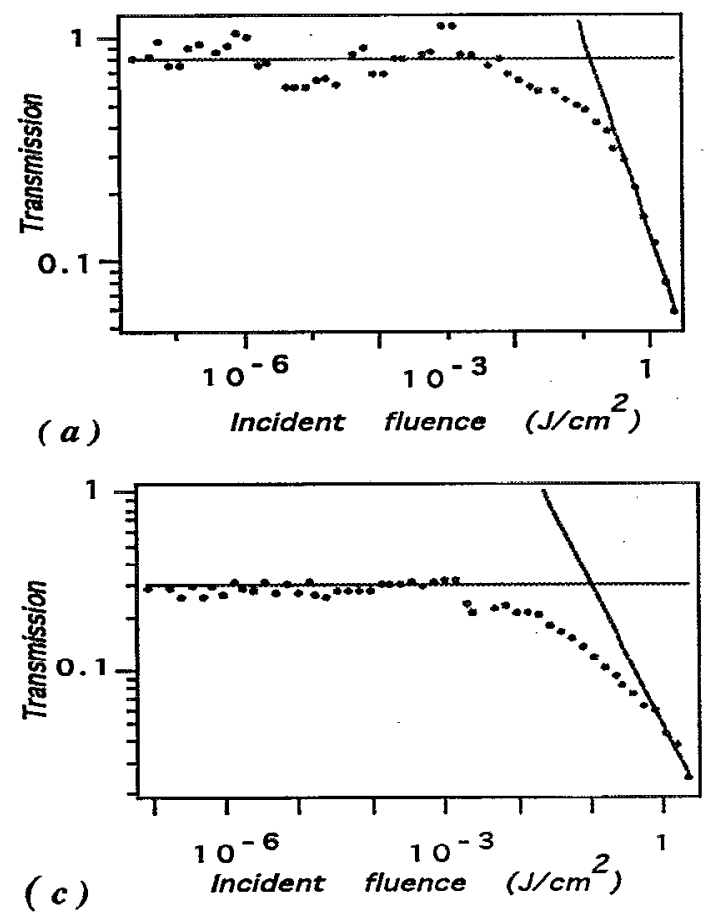
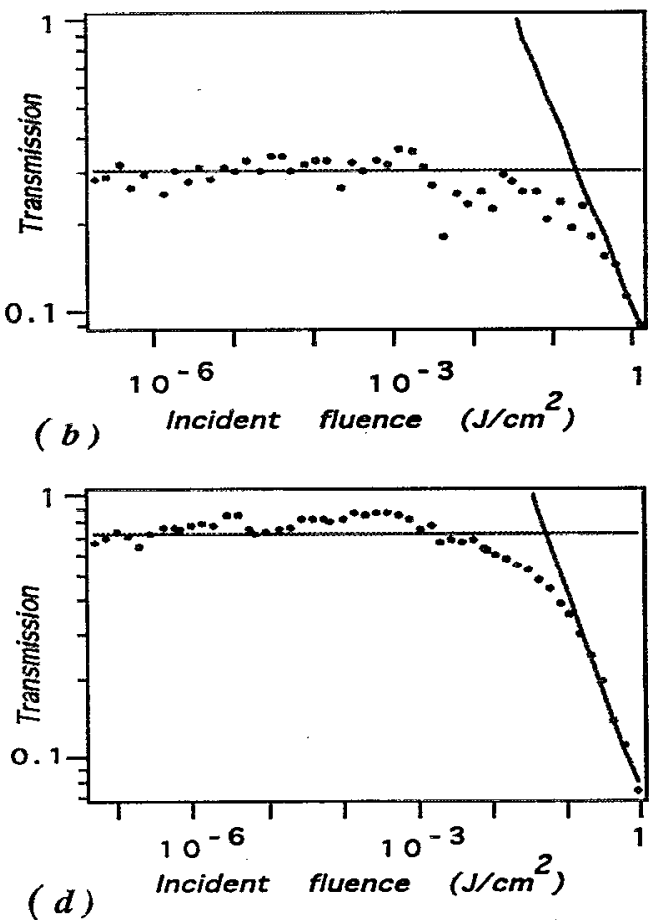

(d)

FIG. 2. Transmission of APC vs incident fluence: (a) in an ethanol solution, (b) in a TEOS matrix, (c) in a MTEOS matrix, (d) in a VTEOS matrix.

matrix interactions. We have already shown that such modifications occur in gels doped by a saturable absorber (Malachite Green) $)^{9,10}$ where both the size and the chemical composition of the substituted organic groups notably modify those interactions and consequently the recovery times of the excited dye molecules.

Xerogel samples were about $1 \mathrm{~mm}$ thick. In order to compare the results obtained, respectively, on the gel samples and on reference solutions, these solutions were placed in $1 \mathrm{~mm}$ thick cells. Drying of the xerogels classically involves an important shrinkage of the samples, leading to an increase of the actual dye concentration. Therefore the dye concentrations of our reference solutions have been chosen to be approximately the same as the dye volumic concentrations in the solid matrices.

The reference solution of APC was prepared with ethanol $\mathrm{C}_{2} \mathrm{H}_{5} \mathrm{OH}$ as the solvent, with a concentration of $4 \times 10^{-3} \mathrm{~mol} / \ell$, which is supposed to be the actual APC volumic concentration in the gel sample after shrinkage (whereas its concentration in the original sol was $4 \times 10^{-4}$ $\mathrm{mol} / \ell$, i.e., assuming that shrinkage reduces the volume to the tenth of its initial value). $\mathrm{C}_{60}$ was studied with benzene $\mathrm{C}_{6} \mathrm{H}_{6}$ as the solvent, with a concentration of $1.4 \times 10^{-4}$ $\mathrm{mol} / \ell$ in the solution and in the final xerogel.

Both series of measurements (successively on gel samples and on reference solutions) were made under the same experimental conditions. Incident radiation consisted of an $8 \mathrm{~ns}$ long pulse at a wavelength $\lambda-532 \mathrm{~nm}$ obtained from a frequency doubled Nd-YAG laser with energies up to 5 $\mathrm{mJ}$. The laser beam was focused on the samples with a diameter of about $500 \mu \mathrm{m}$ and transmitted light was received and measured with a calibrated photodiode.

Absorption spectra of the reverse saturable absorbers, both in solutions and in gels, show that the green incident radiation (at $\lambda=532 \mathrm{~nm}$ ) is on the short wavelength edge of the principal absorption band of these molecules.

Figure 2 shows the evolution of the transmission of aluminophthalocyanine molecules as a function of the increasing incident fluence (energy per surface unit), in soIution (a) as well as enclosed in a gel matrix (b), (c), and (d). Classical behavior ${ }^{5}$ is observed in the ethanolic solution of APC [Fig. 2(a)]. Above a region where the transmission is initially linear and constant, it breaks down very rapidly beyond a fluence threshold of about $10^{-1} \mathrm{~J} / \mathrm{cm}^{2}$. Fluence thresholds are estimated as the point of intersection between the straight lines corresponding to each region of the graphs (see linear interpolation on Figs. 2 and 3 ). Values of the nonlinear threshold intensity $I_{\text {th }}$ are obtained by dividing these fluence saturation thresholds by the duration of the optical pulses ( $8 \mathrm{~ns}$ ). The constant part of the transmission curve (linear absorption) leads, for APC in solution, to a value of about $7 \times 10^{-18} \mathrm{~cm}^{2}$ for the ground-state absorption cross-section $\sigma_{g r}$ which is in agreement with previous studies ${ }^{1,2}$ on this type of organic molecules. Assuming that the incident nonlinearity threshold intensity $I_{\text {th }}$ can be given by: ${ }^{1}$

$$
I_{\mathrm{th}}=h v / \sigma_{g r} \tau_{g r}
$$

where $h v$ is the energy of an incident photon, the value of $I_{\text {th }}$ yields a ground-state recovery time $\tau_{g r}$ of about 3 ns. These first measurements do not allow us to give a precise value of the excited-state absorption cross-section $\sigma_{e x}$, but the decrease of the transmission beyond $I_{\text {th }}$ clearly shows that $\sigma_{e x}>\sigma_{g r}$

Figures 2(b)-2(d) present the same evolution study when APC is encaged in, respectively, TEOS, MTEOS, 

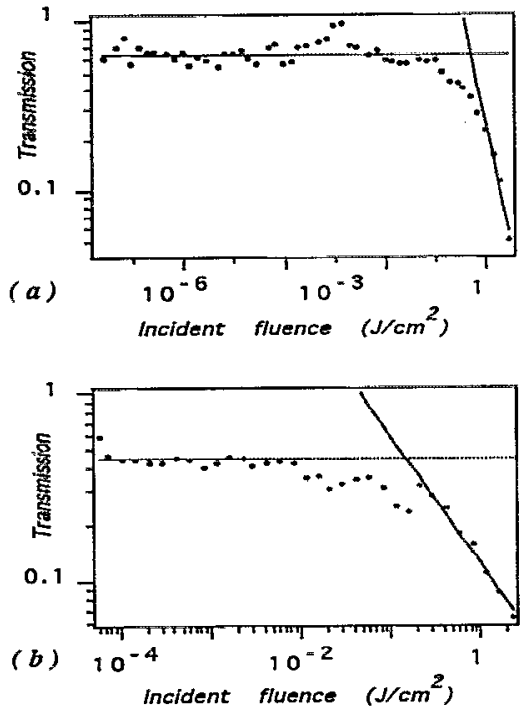

FIG. 3. Transmission of fullerene $C_{60}$ vs incident fluence: (a) in a benzene solution, (b) in a VTEOS matrix.

and VTEOS based silica matrices. As we expected, a good reverse saturable absorption behavior can be obtained even when the molecules are enclosed in a solid gel matrix. In all instances, the value of $I_{\text {th }}$ does not seem to be notably different from that measured in solution. Values of $\sigma_{g r}$ calculated from these curves $\left(10^{-18}-5 \times 10^{-18} \mathrm{~cm}^{2}\right)$ are slightly smaller than that obtained in the ethanol solution. Recovery times $\tau_{g r}$ (over 10-20 ns) are longer than the one evaluated when the aluminophthalocyanine molecules freely move in their ethanolic solution.

The same comparison can be made between the transmission evolution of fullerene $C_{60}$ in a benzene solution [Fig. 3(a)] and that of $\mathrm{C}_{60}$ in a VTEOS gel matrix [Fig. 3 (b)]. Even encaged in a solid medium, the $\mathrm{C}_{60}$ molecule clearly remains a reverse saturable absorber. The nonlinearity threshold (between $10^{-1}$ and $1 \mathrm{~J} / \mathrm{cm}^{2}$ ) does not significantly vary when the molecules are enclosed in the pores. On the contrary, the linear transmission value of the doped gel sample at $532 \mathrm{~nm}$ is smaller than that of the benzene solution. Consequently the ground-state absorption cross-section $\sigma_{g r}$ slightly decreases from $12 \times 10^{-17}$ $\mathrm{cm}^{2}$ in the benzene solution to $7 \times 10^{-17} \mathrm{~cm}^{2}$ in the gel matrix. Besides the ground-state absorption recovery time $\tau_{g r}$ follows the same evolution as for aluminophthalocya- nine: it increases from about 50 ps in solution to about 270 ps when $\mathrm{C}_{60}$ dopes a xerogel matrix.

In both cases, $\mathrm{APC}$ and $\mathrm{C}_{60}$, we thus found that the nonlinearity (or saturation) threshold $I_{\text {th }}$ is not significantly modified when the molecules are trapped in the gel pores. Nevertheless, their ground-state absorption crosssection $\sigma_{g r}$ seems to slightly decrease, whereas their ground-state absorption recovery time $\tau_{g r}$ increases. According to Eq. (1), these opposite evolutions do not contradict the relative invariability of $I_{\mathrm{th}}$ we observed. Moreover, we have already shown ${ }^{9}$ in the case of a saturable absorber (Malachite Green) that, in the type of xerogel we use, the movements of the dye molecules are impeded by the solid matrix. This generally leads to an increase in the $S_{1} \rightarrow S_{0}$ relaxation time, i.e., in $\tau_{g r}$ in comparison to that measured in solution. This interpretation seems to be also valid for reverse saturable absorbers like APC. Further experiments are required to show the influence of the features (size, polarizability,...) of the organic groups (methyl, vinyl) which cover the internal surface of the xerogel pores on the values of $\sigma_{g r} \tau_{g r} \sigma_{e x}$, and $\tau_{e x}$, as well as to directly measure the ground-state recovery time $\tau_{g r}$

As a conclusion, we have shown that usual reverse saturable absorbers still possess their characteristic properties when they are encaged in the pores of a solid xerogel matrix. Only $\sigma_{g r}$ and $\tau_{g r}$ seem to have slightly different values from those observed with the same molecules in solution, $\sigma_{g r}$ decreasing while $\tau_{g r}$ becomes longer. These materials may have large applications as reverse saturable absorbers for mode locking or pulse shaping in solid medium lasers or as solid optical limiters.

${ }^{1}$ D. J. Harter, M. L. Shand, and Y. B. Band, J. Appl. Phys. 56, 865 (1984).

${ }^{2}$ D. J. Harter, Y. B. Band, and E. P. Ippen, IEEE J. Quantum Electron. QE-21, 1219 (1985).

${ }^{3}$ A. Penzkofer, Appl. Phys. B 46, 43 (1988).

${ }^{4}$ B. G. Kushner and J. A. Neff, Mater. Res. Symp. Proc. 109, 3 (1988).

${ }^{5}$ D. R. Coulter, V. M. Miskowski, J. W. Perry, T. H. Wei, E. W. Van Stryland, and D. J. Hagen, SPIE 1105, 42 (1989).

${ }^{6}$ A. Kost, L. Tutt, and M. B. Klein, OSA Tech. Dig. Ser. 12, 582 (1992).

${ }^{7}$ P. D. Fuqua, K. Mansour, D. Alvarez, Jr., S. R. Marder, J. W. Perry, and B. S. Dunn, SPIE 1758, 499 (1992).

${ }^{8}$ F. Chaput, J. P. Boilot, F. Devreux, M. Canva, P. Georges, and A. Brun, MRS Proc. 271, 663 (1992).

${ }^{9}$ M. Canva, G. Le Saux, P. Georges, A. Brun, F. Chaput, and J. P. Boilot, Chem. Phys. Lett. 176, 495 (1991).

${ }^{10}$ M. Canva, P. Georges, A. Brun, F. Chaput, and J. P. Boilot, SPIE 1758, 538 (1992). 